\title{
LA REFORMA CONSTITUCIONAL DE 1910, HACIA EL ESTADO DE DERECHO EN COLOMBIA ${ }^{83}$
}

The constitutional reform of 1910, to the rule of law in Colombia

\author{
$\underline{\text { Lascario Jiménez Lambis }}{ }^{84}$
}

Fecha de recepción: 11 de marzo de 2017

Fecha de aceptación: 25 de mayo de 2017

SUMARIO: 1. Introducción; 2. El estado de Derecho; 3. Fundamentos y características aportaciones a una teoría jurídica; 4. El caso colombiano; 5. Conclusiones; 6. Bibliografía

${ }^{83}$ Articulo derivado de mi tesis de pregrado en derecho de la Universidad de Cartagena.

84 Profesor catedrático universidad Cartagena, Historiador y Abogado magister en historia. https://orcid.org/0000-0001-5317-3501 Email: sabalojl@hotmail.com 


\section{COMO SE CITA ESTE ARTíCULO (APA 6)}

Jiménez Lambis, Lascario (2018). La reforma Constitucional de 1910, hacia el estado de derecho en Colombia. Revista Jurídica Mario Alario D’Filippo, Vol. X Nº. 20, pág.95 - 110

\section{RESUMEN}

El presente trabajo se centra en mostrar, que, si bien es cierto que Colombia tiene en la región una larga trayectoria constitucional, es solo con la reforma de 1910 planteada por los republicanos, donde comienza a gestarse un verdadero y sólido estado de derecho en nuestro país, cuando esta reforma le otorga a la corte suprema la guarda de la constitución.

La argumentación sobre la cual nuestra hipótesis descansa, es que esta reforma representa un paso importante en la historia jurídica del país en lo relativo a la independencia de las ramas del poder público en la consecución de sistemas de control que garanticen con mayor eficacia la coherencia del ordenamiento jurídico; y la consolidación de autoridad de la ciudadanía para definir los rumbos de su historia.

\section{Palabras Claves}

Estado de derecho, constitución, reforma constitucional, republicanismo.

\section{ABSTRACT}

The present paper pretends to show that although it is true that Colombia has a long constitutional trajectory in the region, it is only with the 1910's reform proposed by the republicans, that a true and solid rule of law begins to develop in our country, when this reform gives the Supreme Court the guardianship of the constitution.

The argument of our hypothesis, is that this reform represents an important step in the legal history of the country related to the independence of branches of public power in the achievement of control systems that ensure more effectively the coherence of the legal system; and the consolidation of the authority of citizens to define the course of their history.

\section{Key Words}

Rule of law, constitution, constitutional reform, republicanism. 


\section{INTRODUCCIÓN}

En Colombia el siglo XX se inició, entre otras cosas, con dos experimentos políticos que marcaron buena parte de la vida nacional durante los tres primeros decenios de esa centuria: por un lado, el quinquenio de Rafael Reyes, (1904- 1909), años en los que el gobierno nacional hasta cierto punto relego a un segundo plano las direcciones del bipartidismo histórico, y busco apoyo en los sectores empresariales emergentes que se habían formado y fortalecido durante el periodo de la regeneración; Reyes con su lema "menos política y más acción" se preocupó por conducir a la nación por el desarrollo de una economía "moderna", y ya en el poder tomo medidas que generaron oposición en el seno de las elites tradicionales.

Por otra parte, al quinquenio le sucedió la Unión Republicana (1909-1914), conformada por una alianza entre los conservadores históricos y una importante fracción del liberalismo dirigido por el general Benjamín Herrera, pacto que replanteo las relaciones entre los partidos tradicionales y le mostró al liberalismo la posibilidad de regresar al poder. Los republicanos desplegaron un programa de convivencia política civilizada, efectivo en la reforma constitucional de 1910 que le permitió al país gozar de varias décadas de paz, estabilidad y desarrollo sin precedentes en la historia nacional; las ideas republicanas que marcaron la reforma constitucional de 1910 fueron la moderación, el civilismo, las libertades y el respeto a la constitución y la ley; una nueva conceptualización de la política y de gobierno, en esencia una orientación de modernidad política que tiene como núcleo la conducción del estado por el respeto al derecho a la razón y a las ideas seculares. El Estado de Derecho es un aporte del liberalismo a la democracia y puede ser definido como la sujeción de la actividad estatal a la constitución y normas aprobadas conforme a los procedimientos que aquella establezca. Con esto se pretende garantizar el funcionamiento responsable y controlado de los órganos que detentan el poder; el ejercicio de la autoridad conforme a disposiciones conocidas y no retroactivas en términos perjudiciales, salvo en situaciones realmente excepcionales. Y por último la primacía de los derechos individuales, sociales, culturales y políticos de las personas. Lo anterior tal como fue concebido por los autores alemanes del siglo XIX y comienzos del XX, convierte a este modelo de gobierno en el estado de la racionalización en el ejercicio del poder como garantía de los miembros de la sociedad.

El acto legislativo número 9 de 1905 dio la posibilidad de convocar a una asamblea nacional constituyente conformada por representantes escogidos por las municipalidades, esta asamblea fue bipartidista y se conformó no por los delegatarios recomendados por el gobierno de turno sino por elecciones indirectas, en estas elecciones el partido republicano salió victorioso, aunque con el realineamiento de fuerzas entre los dos partidos; muchos militantes republicanitas se adjuntaron a sus viejos partidos. La asamblea se instaló el día 15 de mayo de 1910 a las 2 de la tarde con un total de cuarenta y un miembros los cuales eligieron a la mesa directiva así: presidente Dr.: Ramón Arango; Primer Vicepresidente, Eloy Pareja; Segundo Vicepresidente, Dr. 
Carmelo Arango y secretario, Dr. Marcelino Arango." 85 y cuya tarea central era modificar la constitución de 1886.

Fueron propuestos y sometidos a estudios tres proyectos de reforma uno del doctor Nicolás Esquerra, otro del doctor Hernando Holguín y Caro, y el tercero del doctor Pedro María Carreño. Después de acalorados y encendidos debates. La corporación dicto tres actos legislativos dos transitorios y uno de carácter permanente. ${ }^{86}$ La Asamblea Nacional constituyente además de los actos reformatorios que expidió, nombro como presidente de la republica a Carlos E. Restrepo máximo representante de la Unión Republicana el 15 de mayo de 1910 para el periodo constitucional de 1910 - 1914.

Si bien es cierto que los tres actos reformatorios de la constitución ${ }^{87}$ de 1886 que se dieron en el año de 1910, fueron importantes para la nación colombiana, por motivos metodológicos y de interés de este trabajo, a nuestro parecer el último de estos actos es el que reúne las características de una verdadera constitución, y no solo eso, sino es la obra cumbre de la Unión Republicana; donde se sentaron las bases de una nueva manera de concebir lo público y de insertar al estado en las nuevas corrientes de la modernidad política. ${ }^{88}$

\section{El estado de derecho}

Las ideas plasmadas en esta constitución se encaminan a una confrontación política por las vías del derecho y no las de hecho, tan acostumbradas en la época decimonónica colombiana, este es un sentido vital de modernidad política un cambio en la mentalidad y en la dialéctica política para un país deseoso de ingresar a la órbita del capitalismo moderno.

\footnotetext{
85 EL ORTO Magangué, domingo 22 de mayo de 1910.

${ }^{86}$ DE PAULA PEREZ Francisco" Derecho Constitucional Colombiano" Sexta Edición. Bogotá. D.C. 1992. Pág. 122.

${ }^{87}$ El concepto de Constitución lo explica con claridad el jurista colombiano Álvaro Echeverry Uruburu, que partiendo de la concepción weberiana (sistema legal racional de ejercer el poder): "El elemento de lo legal racional se condensa en el concepto de Constitución, que desde el siglo XVIII hasta nuestros días se ha convertido en el instrumento fundamental para limitar el ejercicio del poder, buscando conquistar el ideal de un equilibrio entre el individuo -amparado por una serie de libertades y derechos inviolables consagrados en el texto constitucional- y el poder del Estado. El propósito esencial de la democracia liberal está encaminado, por tanto, a lograr un ejercicio restringido del poder (por medio de un sistema normativo cuya más alta expresión es la Constitución y controlador mediante la fragmentación de las tareas del poder (legislar, ejecutar, administrar y juzgar) entregadas a distintos detentadores independientes y autónomos (orgánico legislativo, ejecutivo-gobierno y judicatura). Así como simple punto de partida, entendemos por Constitución, el conjunto de prescripciones jurídicas (consuetudinarias o positivas) reguladoras de las instituciones políticas que conforman el Estado de una formación social particular.

88 En esencia, por modernidad política entendemos lo que Norbert Lecher nos propone: "El proceso de desencantamiento con la organización religiosa del mundo. La sociedad religiosa se caracteriza por la anterioridad y alteridad absoluta de un principio divino como garantía inviolable del orden. La modernidad consiste en la ruptura con esa fundamentación trascendente y la reivindicación de la realidad social como un orden determinado por los hombres". Véase: LECHER, Norbert. Los partidos interiores de la democracia. Subjetividad y política. México: Fondo de Cultura Económica. 1995. PP. 156-158. Así mismo, Jan Jaques Rousseau teorizó sobre el nacionalismo moderno: "La Patria son las leyes, las costumbres, el gobierno, la constitución, la manera de ser que resulta de todo eso. La Patria está en las relaciones del Estado y sus miembros: cuando esas relaciones cambian o se destruyen, la Patria se desvanece". Véase: Hans Kohnin.

Historia del nacionalismo. México: F. C. E. p. 557. En suma, abordamos el concepto de modernidad política, como la secularización del Estado, el acercamiento de la política a la razón y colocando la Fe en un nivel subordinado
} 
Esto nos conduce a una visión laica de las cosas, separar de la lucha partidista los fanatismos religiosos y construir tolerancia e imparcialidad en el manejo del Estado; sin embargo, difícilmente una cultura profundamente católica como la colombiana se cambia a laica de un plumazo jurídico. Razón por la cual el encabezado del acto legislativo número 3 de 1910, reformatorio de la constitución nacional, se redacta así:" En el nombre de dios, fuente suprema de toda autoridad, la asamblea nacional de Colombia, decreta..." 89

Un editorial del tiempo resume el ideario republicano así:

\begin{abstract}
"Enemigo de los dogmas banderizos; orientado hacia las reformas sociales; adverso a las intromisiones del clero y del ejército en la política; defensor de las libertades públicas; amigo de las "soluciones moderadas"; "convencido del poder incontrastable de las ideas en una lenta evolución pacífica hacia un futuro cada vez mejor". Entre los valores proclamados, destacaba la "paz interna", como "necesidad imperiosa y condición indispensable de todo progreso y de toda vida"90.
\end{abstract}

Para alcanzar la paz fue necesaria la alternabilidad de los partidos en el gobierno esto no solo obedeció a una disposición positiva del derecho constitucional, sino a una ley de necesidad social. Descartada la genealogía de los gobiernos humanos por derecho divino, e incorporada la igualdad legal entre los cánones indiscutibles de la modernidad política, ninguna casta ni partido puede reclamar el privilegio de regir los destinos de los pueblos.

Por consiguiente, en derecho abstracto es igualmente fundado y respetable el que tiene cada uno de los partidos colombianos a tomar las riendas del gobierno si ellos, cuando han prevalecido o cuando prevalecen, sostiene lo contrario, fundándose el uno en que tiene el monopolio de la libertad y el otro el monopolio del orden; lo hacen escudándose en el derecho de la fuerza, pero no en la fuerza del derecho.

Al examinar la realidad histórica de esta nueva fuerza política, La Unión Republicana demuestra que no solo alcanzó a ser una coalición provisional de grupos moderados en pos de modificar la constitución de 1886.

Aunque Logrado ese propósito, cada cual regreso a sus toldas partidistas y los planteamientos de Restrepo, en buena parte, marcan la historia jurídica constitucional del país. Uribe dirigió la oposición al gobierno de Restrepo y el conservatismo de Marco Fidel Suárez reafirmo el carácter católico de su partido.

89 POMBO, Manuel Antonio y Guerra José Joaquín. Constituciones de Colombia. Bogotá: Biblioteca popular de cultura colombiana. 1951.Pág.322

90 EL TIEMPO(Editorial),26 de enero de 1920 
No obstante, la desaparición de La Unión Republicana nos lleva a ver un fracaso, pero con sus respectivos matices. En el sentido de que, si bien cada partido volvió a su origen sectario, como el Conservador en cabeza de Laureano Gomes"91; así como la persistencia de la hacienda tradicional como núcleo económico nacional o un Estado con una pesadez burocrática, las ideas republicanas permearon en algo la mentalidad política colombiana. La Reforma Constitucional de 1910 estableció una relativa convivencia entre ambos partidos que apelaron en cierta medida a las vías constitucionales para dirimir sus diferencias. Así como el reconocimiento de las minorías políticas y su representatividad; el derecho de la libre asociación, recordemos los primeros sindicatos obreros; como también la libertad de Prensa. Luego, todos estos elementos corroboran, en cierta forma, la llegada de la modernidad política a la nación colombiana por la vía de la Unión Republicana.

\section{Fundamentos y características aportaciones a una teoría jurídica.}

Desde los inicios de las sociedades humanas el hombre ha tenido varias formas de organización pero la forma más avanzada ha sido y es el estado ; este a lo largo del tiempo se le han dado diferentes significaciones, entendamos que el estado ante todo tiene como fin generar las condiciones que propicien el bienestar, de toda sociedad; para León Duguit el estado es "una agrupación humana fijada sobre un territorio determinado donde los más fuertes imponen su voluntad a los más débiles" 92 y establece una diferencia entre gobernantes y gobernados.

Así mismo para Francisco Porrúa" el estado es una sociedad humana establecida en el territorio que le corresponde, estructurada y regida por un orden jurídico que es creado, definido y aplicado por un soberano para obtener el bien público temporal formando una institución con personalidad moral y jurídica." 93

Para Vladimiro Naranjo "el estado en sentido amplio puede entenderse como un conglomerado social, político y jurídicamente constituido, asentado sobre un territorio determinado sometido a una autoridad que se ejerce a través de sus propios órganos y cuya soberanía es reconocida por otros estados"94.

Estas definiciones nos ponen de relieve unas características que hacen del estado un ente vivo que se transforma al ritmo de las sociedades; y que se legitima en gran medida en la legalidad de

\footnotetext{
91 BRUGMAN Catalina "el fracaso del republicanismo en Colombia: 1910-1914 cap. II. Bogotá :universidad de los Andes .Revista Historia Critica 21.P.91-110

92 Duguit León" Manuel de Derecho Constitucional: Teoría General del Estado, el Derecho y el Estado, las Libertades Públicas .editorial. comares.2005.

93 Porrúa Francisco "Teoría del Estado" Ed. Porrúa. México 32ed. 1999.

94 Naranjo Meza Vladimiro "Teoría Constitucional E Instituciones Políticas" Ed Temis 2003. Bogotá.
} 
su origen de su gobierno y del ejercicio del mismo. Para tener un criterio claro del tema que nos ocupa es necesario establecer algunas reflexiones de lo que se denomina Estado de Derecho.

El concepto Estado de Derecho es un término que está integrado por dos elementos, uno el estado y otro el derecho, desde la antigüedad pasando por la época medieval, la moderna y la contemporánea estos dos conceptos han sido utilizados pero de manera separada; quien utiliza por primera vez el termino estado de derecho es el jurista alemán Robert von Mohl en su obra "derecho ley normatividad y estado" 95 en 1830, pero este término es desarrollado plenamente en el siglo XX por una variedad de juristas dentro de los cuales se encuentra Hans kelsen quien se refiere al estado de derecho como un término" carente de sentido porque derecho y estado son conceptos idénticos y sinónimos; continua diciendo que el estado no es sino la suma total de normas que ordenan la coacción es así coincidentemente con el derecho positivo donde el estado ejerce la coacción" 96.

Otro autor que es uno de los pioneros del estudio del estado de derecho es Edgar Bodenheimer, este autor plantea que el estado despótico sería un estado de derecho, concebido en que la ley del déspota es la que impera ${ }^{97}$. Así se puede darse el estado de derecho en un régimen despótico enfrentando de esta manera unas disyuntivas.

Es de anotar que para el caso del estudio del estado de derecho en América latina es de suma importancia tener como referente la obra de Guillermo O Dornell, quien plantea que en América latina la mayoría de los países recientemente democratizados no se encaminan hacia un régimen democrático representativo e institucionalizado ni parece siquiera que lo vayan a hacer en un futuro previsible, son poliarquías pero de una clase diferente de la cual no existe toda una teoría y añade además que uno de los fracasos de los estados de derecho en América Latina es que no han logrado extender su dominio de manera homogénea en todo su territorio ${ }^{98}$.

Colombia no ha sido ajena al estudio del estado de derecho autores como Olga Maestre de Tabón, Diego Estrada Álvarez y José Iván Ortiz, son algunos entre muchos autores nacionales que se han interesado en estudiar el tema en nuestro país. El concepto Estado de Derecho es intrínsecamente controvertido, siendo una de las claves la filosofía jurídica y política contemporánea, sus rasgos y caracteres hoy continúan siendo discutidos. Pero estando conscientes de la existencia de diferentes interpretaciones; Siempre pervive un elemento

\footnotetext{
95 Von Mohl Robert” Derecho ley ,Normatividad y Estado" Frankfurt .1930

${ }^{96}$ Kelsen Hans "Teoría General de Estado "Editorial. Colofon.México. año 2000

97 Bodenheimer. Edgar. "Teoría del Derecho" FCE .México 1974.

98 Carbonell miguel, Orozco Luis Wistano, Vásquez Rodolfo" Estado de Derecho, Conceptos, Fundamentos y Democratización en América Latina" siglo XXI Editores. México. 2002.
} 
fundacional conceptual compartido que permite un mínimo de comprensión en las interpretaciones en los que el concepto se emplea como:

1) Imperio de la ley (sometimiento del poder público y de los particulares al derecho)

2) Gobierno de las leyes frente al gobierno de los hombres.

3) Garantía de un sistema de derecho.

La existencia de un orden jurídico, de un sistema de legalidad, no autoriza a hablar sin más de estado de derecho, designar como tal a todo estado por el simple hecho de que se sirve de un sistema normativo constituye una imprecisión conceptual que solo lleva a veces intencionalmente a confundir. ${ }^{99}$

Para Elías Díaz se necesita mucho más que un sistema de legalidad para que estemos ante un estado de derecho por muy incipiente que este sea; y expresa que son cuatro las condiciones que deben de existir para que se esté en presencia de un estado de derecho:

1) Imperio de la ley

2) División de poderes

3) Legalidad de la administración

4) Derechos y libertades fundamentales ${ }^{100}$

Pero la verdadera razón del estado de derecho anota Díaz es la lucha contra la arbitrariedad y el despotismo del poder político en nombre de las libertades fundamentales ${ }^{101}$

Otros autores como diego Estrada Álvarez consideran que son principios fundamentales ideológicos y políticos del modelo liberal de estado de derecho:

1. La defensa del individuo como valor central de la sociedad, reflejada ella político jurídicamente en la reivindicación de los derechos humanos de primer generación, o como lo consagra el constitucionalismo colombiano. Los derechos civiles y políticos, definidos como tales en la Constitución de 1886 y en la Constitución de 1991 como DERECHOS FUNDAMENTALES.

2. La libertad como regla general, referida específicamente a esos derechos civiles y políticos (prohibición de la esclavitud, la servidumbre y la trata de seres humanos, libertad de empresa, de pensamiento, de asociación, de escoger profesión u oficio, de cultos, de

\footnotetext{
99 Díaz Elías "estado de derecho y sociedad democrática" cuadernos para diálogos, Madrid 1973Pag.13.

100 Elías Díaz" Estado de Derecho: exigencias internas, dimensiones sociales" sistemas № 125.1995.Pag 11.

101 Op Cit: Pág. 151.
} 
expresión, prensa e información, de desarrollo de la personalidad, de locomoción y domicilio, de profesiones y oficios, de enseñanza, libertad individual (habeas corpus, inviolabilidad del domicilio e inmunidad penal), de elegir y ser elegido, de asociación, entre los más conocidos.

3. La soberanía del pueblo - nación (o soberanía nacional), supuesta expresión de la voluntad popular (debe recordarse qué era el pueblo entonces, hacia la época de los orígenes del modelo - el Tercer Estado de Sieyés-), que se expresa a través del voto, dentro del esquema de democracia representativa, previa y opuesta a la democracia participativa. 4. La desconfianza frente al poder, por el hecho de ser intrínsecamente un factor de corrupción, así sea relativo, al punto de corromper absolutamente cuando de un poder absoluto se trata. De aquí la necesidad de su división para efectos de los pesos y contrapesos y de los equilibrios y controles, inicialmente propuesta por Montesquieu en su clásica fórmula de los tres poderes, el ejecutivo, el legislativo y el judicial (“EL ESPÍRITU DE LAS LEYES").

5. El pluralismo político, como fundamento de la tolerancia y la democracia, al influjo de las doctrinas de Martín Lutero (el libre examen) y de los filósofos defensores del derecho natural, límites de la validez del derecho humano.

6. El imperio de la ley, general, impersonal y abstracta, por encima del poder personal propio del autoritarismo feudal, como símbolo de la igualdad formal. Todos los ciudadanos son iguales ante la ley, ningún gobernante está por encima de ella, el Estado es la ley y no la persona del rey.

Pero estos principios fundamentales necesitan unos instrumentos para su efectiva aplicación de manera concreta anota el autor los cuales son:

1. Constitución Política Escrita, como marco normativo fundamental, superior o básico, como ley de leyes o vértice superior de la pirámide normativa jurídica.

2. Principio de Legalidad (ceñimiento en el ejercicio del poder a leyes preexistentes con el fin de garantizar la seguridad jurídica o certidumbre del derecho y la salvaguarda de los derechos adquiridos).

3. Separación del poder público (Ejecutivo, Legislativo y Judicial).

4. Existencia de medios de defensa administrativa y judicial de los particulares para controlar los desvíos del poder político institucional (derecho de petición, recursos de la vía gubernativa, acciones contenciosas administrativas y disciplinarias).

5. Enunciación preferentemente escrita de los derechos y libertades individuales reconocidos (Tabla de derechos) y de los mecanismos de garantía de su salvaguarda (acción de tutela, fundamentalmente). 
6.- Procedimientos electorales confiables para la elección de las principales autoridades públicas. ${ }^{102}$

Así mismo la Honorable Corte Constitucional de Colombia en su sentencia c-832 del año 2001 expone los axiomas en los cuales se funda el estado de Derecho que a su consideración son:

El principio de Legalidad y la Responsabilidad Patrimonial del Estado, y en la misma línea sigue diciendo que la garantía de los derechos y libertades de los ciudadanos no se preserva solamente con la exigencia a las autoridades públicas que en sus actuaciones se sujeten a la ley sino que también es en esencia que si el estado en ejercicio de sus poderes de intervención causa un daño antijurídico o una lesión lo repare íntegramente. ${ }^{103}$

De otra parte para Nuria Magaldi citando a Ernst Forsthoff; quien a firma que el estado de derecho se define por ser un edificio sistemático un producto dotado de coherencia lógica en sus elementos individuales; parlamentarismo, división de poderes, independencia judicial, reserva de la ley, principio de legalidad de la administración y derechos y libertades fundamentales. ${ }^{104}$

Es de importancia anotar que en todas las definiciones expuestas se percibe un mínimo de garantías para las libertades individuales, de otra parte en lo preceptuado por la Corte Constitucional en la sentencia C-832 en relación con los axiomas del estado de derecho, queda claro que el estado de derecho se asienta sobre el principio de legalidad y la seguridad jurídica que la vigencia de este producen y aun mínimo de principios que garanticen las libertades del ciudadano.

El fracaso de la revolución alemana del 1848 conlleva a una expansión del positivismo jurídico; donde la burguesía se aleja de la aspiración de lograr un estado nacional; y se adecua a un pensamiento político determinado por las nuevas exigencias de las relaciones de poder. Pero esta misma dinámica creó una fuerza que se alejó de la cotidianidad y del dialogo político mediante la creación de una interpretación jurídica alejada de las presiones; y alimentado por la crisis del modelo de estado y el surgimiento de nuevas realidades como la industrialización y la urbanización de las sociedades modernas, pasando de un estado mono clase a un estado pluriclase y donde el estado no solo debía preocuparse por el derecho a la propiedad sino por otra clase de derechos y donde la interpretación tradicional del derecho basada en el positivismo del siglo XIX entra en crisis ante las nuevas realidades; Esto sin descartar que las constituciones del siglo XIX no eran solo instrumentos para la realización de las garantías individuales (derecho

\footnotetext{
102 Estrada Álvarez Diego" El Concepto Estado de Derecho" en revista Patrios politeia: Pág. 2. Año 2009.

103 Corte Constitucional de Colombia .sentencia C-832 de 2001.MG. ponente Doctor Rodrigo Escobar Gil.

104 Magaldi, Nuria" Procura Existencia, Estado de Derecho y Estado Social" Universidad Externado de Colombia. Bogotá .2007. Pag.107-108
} 
a la propiedad), y de la mayoría democrática sino, sobre todo eran instrumentos para la realización de la unidad nacional de los nacientes estados. 105

\section{El caso colombiano}

Para nuestro caso la constitución de 1886 tuvo como función principal organizar a Colombia como un estado centralizado y unido en su territorio; con autoridades y dotarlo de todas las herramientas necesarias para su libre autodeterminación y el lema bajo el cual su principales ideólogos la sancionaron (Rafael Núñez y Miguel Antonio Caro) fue "regeneración o catástrofe"; los cuales habían recibido en su formación la influencia de Bonald y de Maistre; fundaméntales en la restauración de la monarquía francesa, lo que pudo vislumbrase en la constitución de 1886;

"que era un estatuto enderezado a mantener el principio de la autoridad, donde todo el capítulo de las garantías individuales quedaba a merced del gobierno no era la paz lo que prevalecía, sino la guerra"106

La constitución del 86 restringió las libertades, señalo a la religión católica como la religión oficial, extendió el periodo presidencial a 6 años, no admitía la responsabilidad del presidente por ningún delito, concedía facultades extraordinarias al presidente en caso de guerra, dio facultades al presidente para nombramientos de delegatarios, ministros y gobernadores, con la ley 61 de 1888 ( ley de los caballos); donde recibió luz verde para desterrar, clausurar periódicos, y para limitar y desconocer libertades individuales, en fin para establecer un estado policía; pero lo que a nuestro juicio es lo más interesante para nuestro estudio es que la carencia de control constitucional quedo consignada al prescribir la ley 153 de 1887 el principio de la presunción constitucional, es decir, toda ley debía cumplirse aunque fuera contraria a la carta fundamental. ${ }^{107}$

En páginas anteriores hemos visto con ilustración suficiente los elementos constitutivos del estado de derecho; ahora en las líneas que siguen, haremos un análisis de la reforma constitucional de 1910 en relación con esos elementos.

Comenzaremos por uno de los temas que en las distintas sociedades ha generado polémica y son los delitos castigados con pena de muerte que venían consagrados en el ordenamiento jurídico colombiano; esta pena fue abolida por el articulo 3 y en el Art. (B) de la las disposiciones transitorias de la reforma en mención y sustituida con una pena de 20 años de cárcel. Otro avance lo constituyo el establecimiento de la responsabilidad absoluta del presidente o de quien haga

\footnotetext{
105 Ibídem. Pág. 108.

106 Vásquez Carrizosa Alfredo" El poder Presidencial en Colombia” Bogotá, 1986, Suramericana, pag.207- 208.

107 Buena hora Febres-Cordero Jaime" el proceso Constituyente en Colombia "tercer Mundo, editores, 1991. Pág. 19
} 
sus veces Art (29) para todos sus actos su juez natural el senado de la república y la cámara de representantes será su acusador cuando hayan causas justas; esto es muestra de la implementación de uno de los principales postulados del estado derecho que reza que ningún ciudadano quede por fuera de la acción de la justicia.

Pero quizás los mayores progresos los vemos en materia de justicia en relación a que los magistrados de la corte suprema de justicia y sus suplentes serán escogidos cuatro (4) por el senado y cinco (5) por la cámara de representantes de ternas que envié el presidente y se instaura el sistema de coaptación con la escogencia del presidente de la corte por los propios magistrados, esto rompe con la tradición de los estados del viejo régimen donde el ejecutivo nombraba a los magistrados.

A sí mismo la reforma contempla una novedad que los particulares agraviados por las asambleas o por los consejos municipales con sus actos; pueden acudir los primeros ante los tribunales competentes y los segundos ante un juez donde podrán suspender el acto; de la misma forma la reforma en cuestión plante no solo como fundamento del estado de derecho la propiedad sino el derecho a la indemnización antes que esta sea expropiada con motivos de utilidad pública Art (5). Por su parte la elección de los senadores, continúo siendo de manera indirecta realizada por los consejos electorales Art. (12), cuyos miembros los seleccionaba la asamblea departamental Art. (13); en lo que concierne a los asuntos electorales hubo avances pero no se llegó a estipular el sufragio universal , sino solo para la elección de los consejos municipales, para los demás cargos de elección el voto siguió siendo censitario; " mediante ley 80 del 10 de noviembre de 1910 se dividen los electores para las elecciones en dos clases: uno, que son los colombianos varones mayores de 21 años, que sepan leer y escribir; y los que careciendo de esta condición ,sean propietarios de finca raíz de valor de mil pesos o tengan renta anual de 300 pesos; y otros que son los demás ciudadanos. Los primeros pueden votar en todas las elecciones populares y los segundos apenas en las de concejos municipales y diputados a las asambleas departamentales"108 pero si bien es cierto el voto universal siguió siendo sensitivo es de suma importancia observar como la propia dinámica histórica del país va vislumbrando la apertura de nuevos derecho como el derecho de las minorías consagrado en el Art. (45).

Es de anotar que la reforma plantea avances significativos que llegan a la instauración de un estado de derecho en Colombia, pero a nuestro juicio la mayor innovación que la reforma constitucional introduce y de alguna manera nos lleva a firmar la implementación del estado derecho en nuestro país es lo que se plantea en el Art. (40) y (41) de la reforma. Primero porque implanta la supremacía constitucional es decir la constitución es norma de norma y expresa que

${ }^{108}$ EL LIBERAL.Cartagena.3 de Diciembre de 1910. 
"en todo caso de incompatibilidad entre la constitución y la ley se aplicaran de preferencia las disposiciones constitucionales" quedando de esta manera protegido el ordenamiento de cualquier arbitrariedad o abuso de los operadores de justicia fundamento primario del estado de derecho.

Pero Los antecedentes de la salvaguarda constitucional en Colombia; es importante ubicarlos en la constitución de Cundinamarca que le otorgo en el artículo 24 título $\mathrm{V}$ facultades al presidente de la república para devolver las leyes al congreso por inconstitucionales al momento que le fueran presentadas para su promulgación; a si se establece un tímido control previo de constitucionalidad en nuestro país ; con la reforma constitucional del 18 de julio de 1812 se varió el control y se habilito a la primera cámara de la legislatura "como conservadora de la constitución". Solo hasta el año de 1850, la ley de la administración y régimen municipal encomendó a la corte de justicia el conocimiento de las causas abiertas directas y ciudadanas contra las normas de las cámaras provinciales y los cabildos parroquiales, por razones de inconstitucionalidad; desde esta fecha hasta la Constitucionalización del control constitucional en Colombia, el énfasis cedió en los poderes presidenciales; en los conflictos por constitucionalidad entre el Legislativo y el ejecutivo se resolvieron sin la intervención de otro órgano del poder". ${ }^{109}$ En segundo lugar porque se le "confía a la corte suprema la guarda de la integridad de la constitución; En consecuencia, además de las facultades que le confieren esta y las leyes tendrá las siguientes: Decidir definitivamente sobre la exequibilidad de los actos legislativos que hayan sido objetados como inconstitucionales por el gobierno, o sobre todas las leyes o decretos acusados ante ella por cualquier ciudadano como inconstitucionales, previa audiencia del procurador general de la nación"; con lo preceptuado en este artículo queda plenamente evidenciado un estado de derecho en Colombia. Aunque algunos autores como Alcibíades Paredes Collazos argumentan lo contrario y lo sustenta así: "El estado de derecho es solo una apologética fantasía del pensamiento liberal, y el pretendido sometimiento del estado aun derecho trascendente debemos mirarlo como otro de los muchos desvaríos idealistas que en el mundo han sido". Y en la misma línea prosigue el autor de marras afirmando que "no es el estado el que está sometido al derecho, sino todo lo contrario, son las leyes las que están subordinadas al poder; en otros términos, es la política la que prima sobre el derecho"110 y concluye que el estado de derecho es un mito liberal.

Si bien es cierto el ejercicio del poder se realiza a través de un proyecto político este proyecto político está basado no solo, por el vaivén de la política como tal sino que ese proyecto está sujeto a unas normas imperativas que lo hacen operativo; la política no solo es, una práctica, también al

\footnotetext{
109 Raad Berrio Manuel" Del derecho litigioso al DerechoPreventivo"Ed.Leyer.Bogota.2008.Pag.152-154

110 Paredes Collazos Alcibíades” Estado De Derecho ¿Realidad o Mito Liberal? Y otros ensayos” universidad Santiago de Cali. Cali.2002.pag 12 y 40.
} 
igual que el derecho es una ética donde existen unas normas que van más allá de la voluntad del gobernante y del pópulos que leda la legitimidad a él como tal (gobernante); es decir que el gobernante como máximo representante del estado, y ejecutante de su política, no puede ser un legisbus solutus (estar sin ataduras legales). Un gobernante sin ataduras legales es como un animal fiero que actúa sin dominio.

\section{CONCLUSIONES}

El Estado de derecho en Colombia tiene como fundamento los mismos presupuestos enunciados doctrinalmente desde el siglo XVIII: (1) el principio de separación de poderes, (2) el principio de legalidad, (3) una carta de derechos. Cada uno de esos presupuestos presenta algunas peculiaridades propias de nuestro devenir histórico pero que en definitiva son similares a las que presentan países con un nivel parecido de desarrollo. Así, por ejemplo, debido a que la forma de gobierno tradicionalmente ha sido presidencial, el principio de separación de poderes ha de ser entendido de la manera propia de dicha forma de gobierno, en la que el poder ejecutivo goza de cierta preeminencia y tiene bastante influencia en el diseño y en la ejecución de la agenda legislativa, además por el desprestigio del Congreso y la crisis de los partidos, el poder legislativo no sirve de contrapeso efectivo al Ejecutivo, mientras que el poder judicial ha ido asumiendo un rol protagónico en los últimos años, precisamente porque el diseño constitucional lo salvaguarda en cierta medida de las presiones de los otros restantes poderes y por el amplio catálogo de derechos establecidos en la Constitución y la posibilidad de exigirlos en sede judicial, de tal manera que los jueces cada vez tienen más injerencia en la implementación de políticas públicas. De otro lado El principio de legalidad ha de ser entendido morigerado por el principio de supremacía y eficacia normativa de la Constitución, es decir un principio de legalidad "en el sentido amplio" en el cual se reconoce la preeminencia de los preceptos constitucionales pero la ley sigue teniendo un lugar relevante dentro del sistema de fuentes, y las nociones de reserva de ley y de fuerza y rango de ley siguen siendo importantes para establecer las relaciones entre las distintas normas que componen el ordenamiento jurídico.

La Carta de derechos ya no sólo incluye los típicos derechos de libertad sino también los DESC y los derechos colectivos, lo que por una parte potencia el papel de los jueces encargados de hacerlos efectivos y por otra parte obliga a tomarse todos los derechos en serio, sobre todo en la medida en que se crean instrumentos judiciales para hacerlos exigibles, con el problema que implica que los jueces tomen decisiones con impactos presupuestales y determinen el diseño de políticas públicas.

Creo que la construcción del estado de derecho en Colombia es ante todo un proceso histórico que se inicia precisamente con la reforma de 1910 y que ha sufrido diversas vicisitudes a lo largo de estos dos últimos siglos. Es decir, no basta con la existencia de una Constitución que consagre 
los presupuestos del estado de derecho para que este modelo surja, sino se requiere que se construyan las bases que permitan que cada uno de los elementos que lo conforman sea realmente efectivo. Es decir, de nada serviría que la Constitución establezca la separación de poderes si las instituciones no están lo suficientemente consolidadas para que el ejecutivo acepte las decisiones judiciales que le son adversas y eso en Colombia se ha ido construyendo a lo largo de los años.

En Colombia el progreso jurídico en lo que concierne a los instrumentos "garantista" de los derechos de los ciudadanos y el fortalecimiento del estado de derecho debería utilizarse no solo para garantizar y promover los derechos del individuo y la colectividad sino también para establecer unas condiciones básicas en las que sus aspiraciones legítimas puedan llegar hacer una realidad.

\section{REFERENCIAS BIBLIOGRAFICAS}

\section{Fuentes primarias:}

Acto legislativo № 1, 28 de mayo, 1910

Acto legislativo № 2, 6 de junio, 1910

Acto legislativo № 3,31 Octubre, 1910

\section{Sentencias corte:}

Corte Constitucional de Colombia. Sentencia C-832 de 2001.MG. Ponente Doctor Rodrigo Escobar Gil.

\section{Periódico, papel prensa;}

EL ORTO Magangué, domingo 22 de Mayo de 1910.

EL TIEMPO, Enero 26 de 1920

EL LIBERAL.Cartagena.3 de Diciembre de 1910.

\section{Fuente secundaria:}

\section{Libros, artículos:}

BODENHEIMER, Edgar. "Teoría del Derecho" FCE .México 1974.

BRUGMAN, Catalina. “El fracaso del republicanismo en Colombia: 1910-1914. Cap. II. Bogotá: Universidad de los Andes. Revista Historia Crítica 21.P.91-110

BUENAHORA Febres-Cordero, Jaime" el proceso Constituyente en Colombia "tercer Mundo, editores, 1991. 
Lascario Jiménez Lambis

CARBONELL, miguel, OROZCO, Luis Wistano, VÁSQUEZ, Rodolfo" Estado de Derecho, Conceptos, Fundamentos y Democratización en América Latina" siglo XXI Editores. México. 2002.

DE PAULA Pérez, Francisco" Derecho Constitucional Colombiano" Sexta Edición. Bogotá. D.C.

DÍAZ, Elías “estado de derecho y sociedad democrática” cuadernos para diálogos, Madrid, 1973.

DÍAZ, Elías “Estado de Derecho: exigencias internas, dimensiones sociales” sistemas N² 125.1995.

DUGUIT, León. Manual de Derecho Constitucional: Teoría General del Estado, el Derecho y el Estado, las Libertades Públicas .editorial. comares.2005.

ESTRADA Álvarez, Diego “El Concepto Estado de Derecho” en Revista Patrios Politeia. Año 2009.

KELSEN, Hans "Teoría General de Estado" Editorial. Colofon.Mexico. año 2000

MAGALDI, Nuria" Procura Existencia, Estado de Derecho y Estado Social" Universidad Externado de Colombia. Bogotá .2007.

NARANJO Meza, Vladimiro" Teoría Constitucional E Instituciones Políticas" Ed Temis 2003. Bogotá.

PAREDES Collazos, Alcibíades" Estado De Derecho ¿Realidad o Mito Liberal? Y otros ensayos" universidad Santiago de Cali. Cali.2002.

POMBO, Manuel Antonio y Guerra José Joaquín. Constituciones de Colombia. Bogotá: Biblioteca popular de cultura colombiana. 1951. Pág.322

PORRÚA, Francisco “Teoría del Estado” Ed. Porrúa. México 32ed. 1999.

RAAD Berrio Manuel” Del derecho litigioso al Derecho Preventivo" Ed. Leyer .Bogota.2008.

VÁSQUEZ Carrizosa, Alfredo “El poder Presidencial en Colombia” Suramericana, Bogotá, 1986.

VON MOHL, Robert" Derecho ley, Normatividad y Estado" Frankfurt .1930 